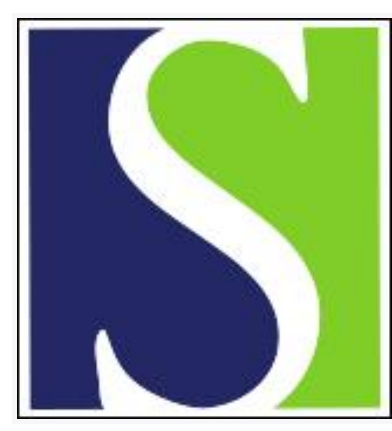

Scand J Work Environ Health 1979;5(3):195-204

https://doi.org/10.5271/sjweh.3093

Issue date: Sep 1979

\section{Effects of work in cold stores on man}

by Enander A, Ljungberg A-S, Holmér I

Affiliation: National Board of Occupational Safety and Health, S-17184 Solna, Sweden.

Key terms: body temperature; climate; cold; cold store; dairy work; discomfort; ergonomics; man; meat cutting; meat packaging; men; perceived temperature; skin temperature; work; work load

This article in PubMed: www.ncbi.nlm.nih.gov/pubmed/20120567

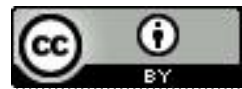




\title{
Effects of work in cold stores on man
}

\author{
by ANN ENANDER, M.A., ANN-SOFIE LJUNGBERG, M.Sc., and \\ INGVAR HOLMÉR, Ph.D. ${ }^{1}$
}

\begin{abstract}
ENANDER, A., LJUNGBERG, A. S. and HOLMER, I. Effects of work in cold stores on man. Scand. $j$. work environ. \& health 5 (1979) 195-204. A work physiological study was conducted during three different types of work in cold stores, i.e., at dairies and in the cutting and packaging of meat. Peripheral cooling, especially of the fingers and hands, was noted in all the subjects. The work load was relatively light for the packers but varied considerably in the dairy work. In both dairy and packaging work, clothing was unsatisfactory in terms of thermal insulation and flexibility. The butchers were subjected to less cooling, as a result of a relatively intense but even work rate and clothing adapted to the work. The subjects were very capable of perceiving temperature changes in the peripheral parts of their bodies. Individual variations were considerable, especially with respect to cooling and the perception of temperature and discomfort.
\end{abstract}

Key words: body temperature, climate, cold, cold stores, dairy work, discomfort, ergonomics, meat cutting, meat packaging, perceived temperature, skin temperature, work load.

A cold climate is a reality in many outdoor jobs and also in indoor work in, e.g., cold stores. The need for a low temperature (below $+10^{\circ} \mathrm{C}$ ) in the storage and handling of food is a complicating factor with regard to a satisfactory work environment.

Occupational exposure to a cold environment may have an adverse effect on man's performance, health and comfort. Cold is regarded by the workers in this kind of work as one of the main causes of accidents, illness and different types of complaints.

The problem of work in a cold climate

1 Occupational Health Department, National Board of Occupational Safety and Health, Stockholm, Sweden.

Reprint requests to: Dr. Ingvar Holmér, National Board of Occupational Safety and Health, .S-171 84 Solna, Sweden. has been studied in laboratories and under field conditions. Several reviews have been published on this topic $(1,2,9)$. Various behavioral effects of exposure to cold have been reviewed by Fox (4). Some field studies on occupational work have been performed in the Scandinavian countries. Workers in the fishing industry were studied with respect to cold both in the laboratory (5) and in the field (11). The biological effect of meat cutting and packaging in low temperatures has also been studied (8). However, there is still a shortage of documentation on the effects during practical work. The present report summarizes a physiological study of work in cold stores in the food industry $(6,7$, 10).

The objectives of the study were to determine energy requirements during work, to record the nature and extent of the effects of exposure to a cold climate and cold 
goods on individuals, and to study the perception of temperature in relation to corresponding objective measurements.

\section{CLIMATE AND ACTIVITY AT THE DIFFERENT WORK SITES}

The following three different types of work in cold stores were studied: (a) storeroom and loading work in a dairy, (b) the cutting down and rough cutting of beef quarters, and (c) the fine cutting and packaging of meat (fig. 1). The climatic conditions are listed in table 1 .

In dairy cold stores $\left(+4^{\circ} \mathrm{C}\right)$ the staff picked out goods according to customer orders and placed these goods onto a floorlevel conveyor belt. The work involved a great deal of movement, lifting, and carrying.

In the meat-cutting unit $\left(+10^{\circ} \mathrm{C}\right)$ the butchers alternated weekly between cutting down and rough cutting beef quarters. Cutting down involved movements with many changes in work position. Lifting of pieces weighing $40 \mathrm{~kg}$ also occurred. The slabs of beef were rough cut into $2-$ to $8-\mathrm{kg}$ chunks. This work consisted mainly of stationary arm work.

Work in the packaging department $\left(+10^{\circ} \mathrm{C}\right)$ involved the additional processing of the chunks of beef produced by the meat-cutting unit. These chunks were sliced, minced or processed in this room. Packaging and price marking also took place there. The work was mainly stationary. Order-filling work in a cold-storage room $\left(+4^{\circ} \mathrm{C}\right)$ was also studied in the packaging department.

\section{MATERIAL AND METHODS}

Approximately eight subjects from the staff were studied at each work site. They were of normal height and weight, and their physical work capacity was moderate or slightly below average. The subjects were men between 19 and 60 years of age, with the exception of three women be-

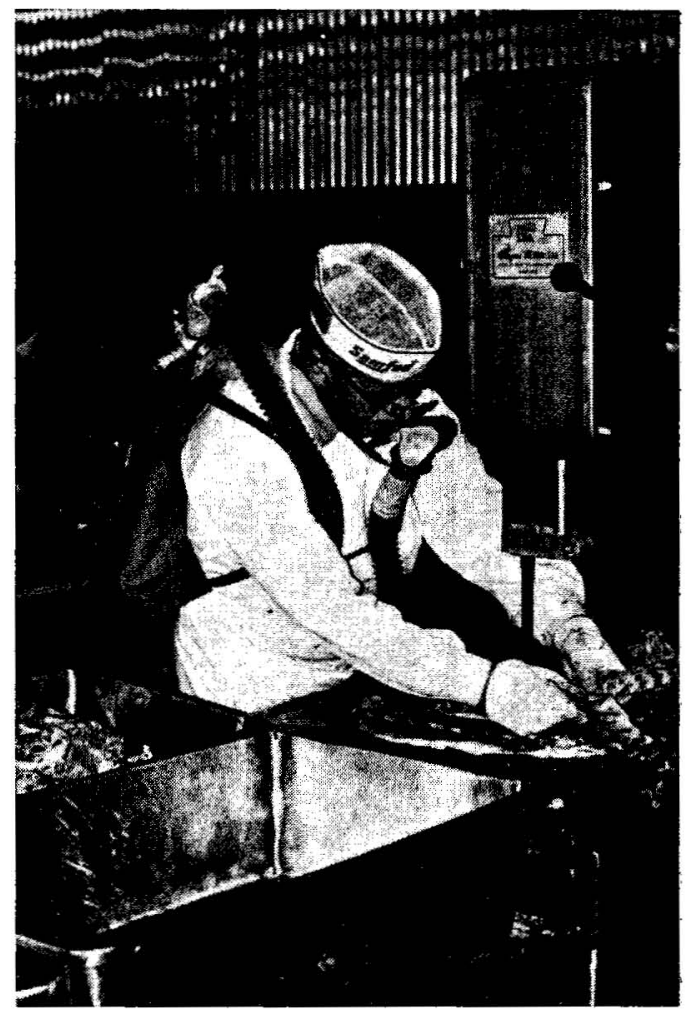

Fig. 1. Measurement of the oxygen uptake of a packer during work in the packaging department.

Table 1. Variation in the temperature, humidity and velocity of the air and the surface temperature of the products at the different work sites.

\begin{tabular}{|c|c|c|c|c|}
\hline \multirow[b]{2}{*}{ Parameter } & \multirow[b]{2}{*}{ Dairy } & \multirow{2}{*}{$\begin{array}{l}\text { Meat } \\
\text { cutting }\end{array}$} & \multicolumn{2}{|c|}{ Packaging } \\
\hline & & & $\begin{array}{l}\text { Packaging } \\
\text { room }\end{array}$ & $\begin{array}{l}\text { Cold-storage } \\
\text { room }\end{array}$ \\
\hline $\begin{array}{l}\text { Air temperature }\left({ }^{\circ} \mathrm{C}\right) \\
\text { Air velocity }(\mathrm{m} / \mathrm{s}) \\
\text { Air humidity }(\% / 0)\end{array}$ & $\begin{array}{c}1-6 \\
0.1-0.4 \\
83-95\end{array}$ & $\begin{array}{c}10-13 \\
<05-85\end{array}$ & $\begin{array}{c}8-15 \\
0.0-0.3 \\
48-73\end{array}$ & $\begin{array}{c}2-5 \\
0.1-0.5 \\
64-75\end{array}$ \\
\hline $\begin{array}{l}\text { Surface temperature } \\
\text { of products }\left({ }^{\circ} \mathrm{C}\right)\end{array}$ & 2 & $0-6$ & $(-9) \quad 2-6$ & $2-6$ \\
\hline
\end{tabular}


tween 19 and 35 years of age in the packaging department. The subjects wore their ordinary workclothing during the work sessions. White cotton clothing was supplied by the company. Most workers wore a short jacket, trousers, underpants, one or two pairs of socks, clogs, and sometimes also undershirts, cotton gloves, aprons or a cap. The estimated clo values varied from 0.8 to 1.2 (3). Clothing in the packaging department was supplemented with an insulating vest and trousers which increased the estimated clo values to $1.0-$ 1.5 .

Each subject was studied for $2 \mathrm{~h}$ during ordinary work on two different occasions. At 20- to 30-min intervals during the measurement sessions the subjects estimated their perception of temperature and discomfort from heat or cold in their body, hands and feet with the aid of two 20point rating scales. Each scale had a neutral midpoint and verbally defined end-points $(+10$ and -10$)$, termed maximal warmth/discomfort from warmth and maximal cold/discomfort from cold, respectively.

Body temperature was measured with an oral (butchers and packers) or rectal (dairy workers) thermometer before and after each session. Skin temperature was recorded with six linear thermistors (accuracy: $\pm 0.5^{\circ} \mathrm{C}$ ) taped on the right side of the body (e.g., the top of the index finger, back of the hand, chest, shoulder or forehead, heel or leg, and big toe). The signals were recorded on a portable, 2-channel tape recorder which also recorded heart rate.

In order for the energy requirements of the work to be calculated, oxygen uptake was determined in the subjects on two different occasions during each work session with the aid of the Douglas-bag technique. The volume of expiratory air from 2-5 min of work was measured with a gas meter, and ventilation (BTPS) was calculated. The oxygen (Beckman OM11) and carbon dioxide (Beckman LB2) concentrations were determined. Oxygen uptake (STPD) was then calculated. Energy requirements were calculated on the basis of oxygen uptake according to the following relationship: $11 \mathrm{O}_{2} / \mathrm{min} \approx$ $350 \mathrm{~W} \approx 5 \mathrm{kcal} / \mathrm{min}$.

During each measurement session, sub- ject activity was noted and regular climatic measurements were made. The surface temperature of the goods, the table, the floor, and the walls was measured with an infrared meter (Raynger).

\section{RESULTS}

\section{Oxygen uptake and heart rate}

The work rate in the dairy cold stores was governed by the need to load the delivery trucks rapidly. This was especially the case during early morning sessions. In conjunction with these sessions, the values for oxygen uptake were found to vary from 0.5 to $1.5 \mathrm{l} / \mathrm{min}$ with individual peaks exceeding $2 \mathrm{l} / \mathrm{min}$ (fig. 2). The mean heart rate during work varied from 90 to 130 beats/min during the early morning and late morning sessions (fig. 3). The work was essentially intermittent with periods of high work intensity with peaks in heart rate exceeding 140 beats $/ \mathrm{min}$ succeeded by rest pauses or lighter work. The individual variation in heart rate was largely ascribable to individual variations in physical work capacity (maximal oxygen uptake). In an assessment of the physiological work load, it was found that the workers periodically utilized $50-70 \%$ of their physical work capacity in conjunction with work peaks.

Physical requirements were lower during the afternoon session. A varying work load resulted in individual values for oxygen uptake ranging from 0.4 to $1.8 \mathrm{l} /$ min. The mean heart rate during afternoon work varied from $75-110$ beats/min and was generally lower than in the morning.

The butchers could usually determine their own work intensity, and they selected an even and moderate work rate. During cutting-down work the mean heart rate varied from $100-110$ beats $/ \mathrm{min}$. Oxygen uptake was found to amount to $0.8-2.1 \mathrm{l} / \mathrm{min}$ during work, corresponding to $35-50 \%$ of the respective individual's physical work capacity. The highest work loads were obtained in conjunction with the cutting down of bull carcasses, especially in work on hard or tough meat. Individual peaks in heart rate of about 140 

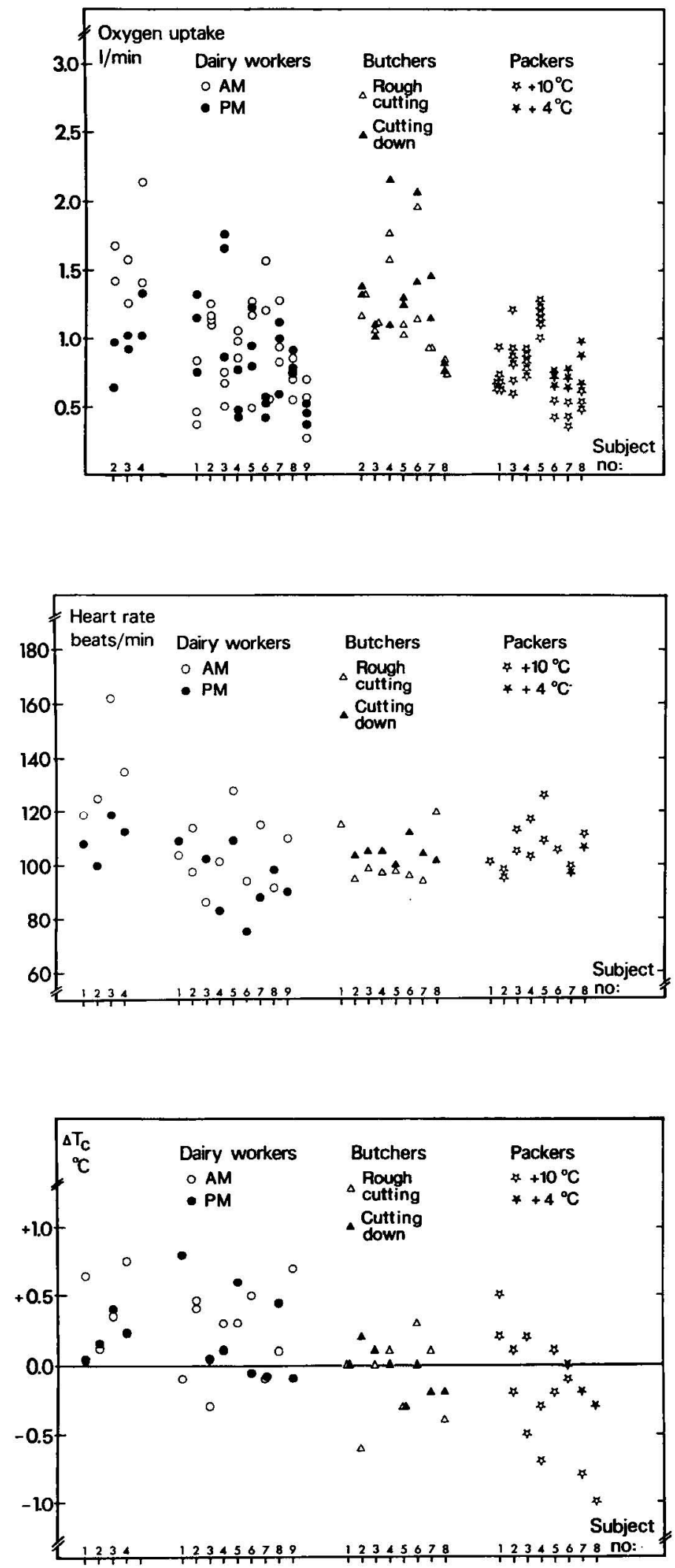

Fig. 4. Change in body temperature $(\triangle \mathrm{Tc})$ after $2 \mathrm{~h}$ of work in the cold for all subjects and measurement sessions.
Fig. 3. Mean heart rate during $2 \mathrm{~h}$ of work in the cold for all subjects and measurement sessions.
Fig. 2. Oxygen uptake values measured on two different ocsession in the cold for all subjects and measurement sessions. casions during each $2-\mathrm{h}$ work 
Fig. 5. Initial values and lowest skin temperatures measured on the fingers for all subjects and measurement sessions. Subjects listed within each group according to the lowest temperature measured.

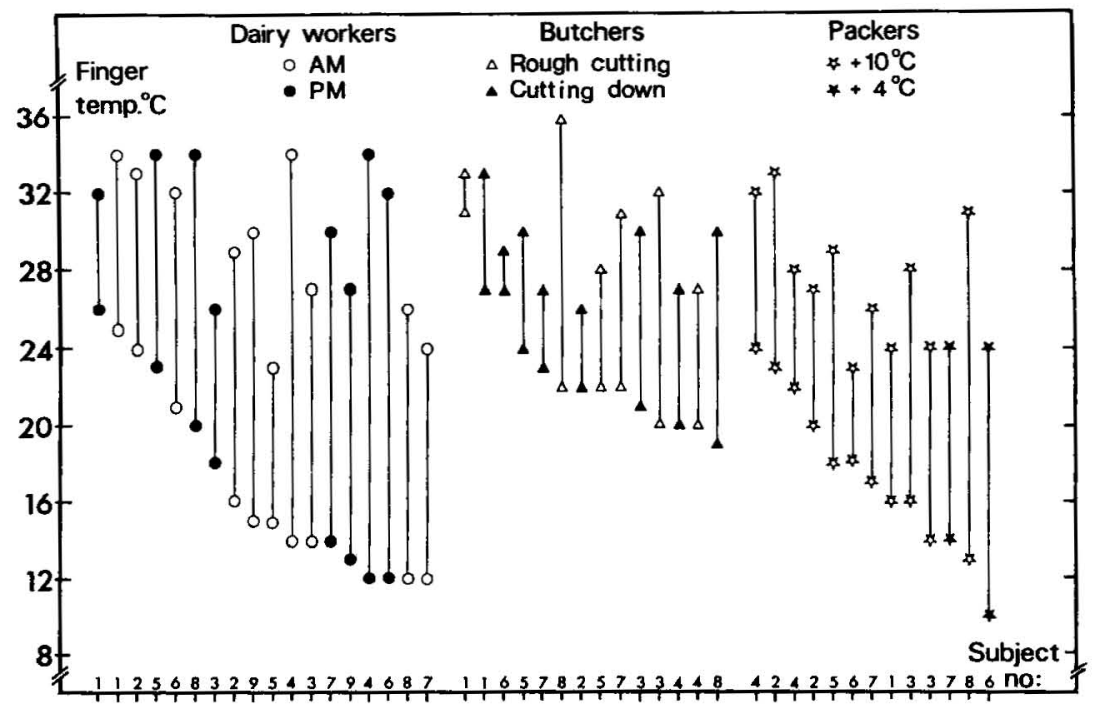

beats/min were then occasionally noted. The work load was somewhat lower during rough cutting, the heart rate being about 8 beats $/ \mathrm{min}$ lower and the values for oxygen uptake also being somewhat lower (fig. 2 and 3).

In the packaging department work intensity was on an even but clearly lower level than in the meat-cutting unit. The oxygen uptake of the men varied from 0.6 to $1.3 \mathrm{I} / \mathrm{min}$. The oxygen uptake of the women amounted to $0.4-0.6 \mathrm{l} / \mathrm{min}$ during work in $10-13^{\circ} \mathrm{C}$. Their work in the coldstorage room (about $+4^{\circ} \mathrm{C}$ ) was somewhat heavier, and oxygen uptake varied from 0.6 to $1.0 \mathrm{l} / \mathrm{min}$ (fig. 2). The mean heart rate averaged $95-120$ beats $/ \mathrm{min}$, peaks occasionally rising to 130 beats/min (fig. 3 ). In general, heart rate remained fairly constant for the packers during the work session, even if the brief pauses and breaks made the work appear to be intermittent. In relation to oxygen uptake, their heart rate was somewhat higher than for, e.g., the butchers, primarily because of the age and sex differences between the groups. The work staff studied in the packaging department mainly consisted of older men, but it also included three women.

\section{Body and skin temperature}

Fig. 4 and 5 show individual values for body and finger skin temperature at the different work sites and sessions. Fig. 6 shows the individual response pattern for skin temperature at different parts of the body of one woman from the packaging department.

In the dairy cold stores an increase in body temperature (rectal temperature) was generally noted during sessions with high activity. Body temperature remained almost unchanged during low-activity sessions.

The hands and fingers were always the coldest parts of the body. Finger skin temperatures of $12-15^{\circ} \mathrm{C}$ were measured for several subjects. The back of the hand was generally a few degrees warmer, 15$20^{\circ} \mathrm{C}$. Skin temperatures on the lower limbs were generally $25-30^{\circ} \mathrm{C}$, while the corresponding values for the feet were $20-25^{\circ} \mathrm{C}$. It is interesting to note that the skin temperature of the chest was $3-4^{\circ} \mathrm{C}$ higher, on the average, for the four subjects from one of the dairies than for the others. For all four of these subjects increases in body temperature were also measured. The explanation of these findings is probably to be found in a higher work intensity at this dairy, which contributed to a higher heat production.

Body temperature (oral temperature) was almost constant during meat-cutting work (fig. 4). However, it dropped 0.2$0.6^{\circ} \mathrm{C}$ in a few subjects.

The lowest skin temperature (finger) 